\title{
Endoscopic Closure of Bronchopleural Fistula using Glue Therapy: A Case Report
}

\section{Sandeep Gupta ${ }^{1 *}$ and Simica ${ }^{2}$}

${ }^{1}$ Consultant Pulmonary and Critical care, Department of Pulmonary Medicine and Critical care, Columbia Asia Hospital, Patiala, India ${ }^{2}$ Department of Anesthesiology, Columbia Asia Hospital, Patiala, India

\begin{abstract}
The occurrence of a bronchopleural fistula (BPF) continues to represent a challenging management problem, and is associated with high morbidity and mortality. Bronchoscopic closure of BPF with instillation of n-butyl-cyanoacrylate glue is an effective, economical, minimally invasive and safe technique for managing BPFs. We present a case that was successfully treated with this method.
\end{abstract}

Keywords: Bronchopleural fistula; Fibreoptic bronchoscopy; n-butyl-cyanoacrylate

\section{Introduction}

Bronchopleural fistula (BPF) is a sinus tract between the bronchus and the pleural space that may result from a necrotizing pneumonia/ empyema (anaerobic, pyogenic, tuberculous and fungal), lung neoplasm, blunt and penetrating injuries, or may occur as a complication of procedures, such as lung biopsy, chest tube drainage, thoracocentesis or may complicate radiation therapy. Clinically it is suspected when the air leak through the underwater drainage system persists beyond 24 hours of its initiation [1]. Mortality rates vary between $18 \%$ and $67 \%$ [2]. The management of BPF is one of the most complex challenges encountered by the chest physicians.

\section{Case Report}

A 52 year old male presented to our emergency department with the chief complaint of breathlessness. The patient was a known case of bronchial asthma with allergic bronchopulmonary aspergillosis (ABPA) and bilateral bronchiectasis. The CT scan showed bilateral pneumothorax, more on the left side. Both the lungs were cystically dilated with areas of consolidation. Intercostal chest drainage was placed on both the right side and left side with persistent air leak was noticed on right sided drainage bag. A diagnosis of BPF was made and antibiotics were started. However, his clinical picture did not resolve with an antibiotic regime and chest tube drainage. At bronchoscopy, the bronchopleural fistula was observed on the right side with air bubbling seen from apical segment upper lobe and on wedging the bronchoscope in right upper lobe segment air bubbling was stopped. After this, $1 \mathrm{ml}$ of n-butyl-cyanoacrylate was applied around the fistula orifice. Still there was a persistent air leak. Another $1 \mathrm{ml}$ of n-butyl-cyanoacrylate was applied and the closure of BPF was confirmed with air bubbling stopped in drainage bag. There was no procedure related complication. Expansion of the lung was achieved. Intercostal tube was clamped on $3^{\text {rd }}$ post procedure day and a repeat chest radiograph was done after 24 hours of clamping showed no reappearance of pneumothorax and no bubbling in air bag. The chest tube was removed successfully on the next morning. On follow up over a period of 2 months, the patient had no relapse of BPF.

\section{Discussion}

BPFs developing as a complication of pleuropulmonary infections may develop at any point of time during the course of illness. The patients who present with a BPF developing late or those who develop the fistula as a complication of suppurative pleuropulmonary diseases are initially managed medically. Medical management should include dependent drainage and reduction of the pleural space, antibiotics, nutritional supplementation and adequate ventilatory management if ventilated [3]. The closure of fistula requires surgical or thoracoscopic interventions which are difficult to carry out in patients with poor lung function. In recent years, a number of non-surgical techniques have been developed for attempting endobronchial closure of BPFs. It should be noted, however, that the efficacy of the endoscopic repair is reduced proportionally with increasing fistula diameter. In cases of a small fistula, or where the surgical risk is high, various bronchoscopic methods have been used to close the fistula. The glue has got remarkable safety and simplicity in its application. It solidifies quickly on exposure to humidity and has got antibacterial effect [4]. Hence, endobronchial sealing of BPF with cyanoacrylate glue is a plausible solution and the technique described appears to be reasonably easy as well as effective.

\section{Conclusions}

BPF is associated with significant morbidity and mortality. Treatment of active infection and life threatening complications should be instituted as early as possible. In cases of smaller fistulas, a bronchoscopic closure can be attempted with satisfactory result.

\section{References}

1. Sahn SA (1995) Pleural disease in the critically ill patient. Intensive care Medicine 3: 720-737.

2. Hollous PH, Lax F, el-Nashef BB, Hauck HH, Lucciarini P, et al. (1997) Natura history of bronchopleural fistula after pneumonectomy: a review of 96 cases. Ann Thorac Surg 63: 1391-1397.

3. Baumann MH, Sahn SA (1990) Medical management and therapy of bronchopleural fistulas in the mechanically ventilated patient. Chest 97 : 721728.

4. Giray CB, Us D, Guney C, Araz K (1993) Antibacterial and cytotoxic effects of N-butyl-2- cyanoacrylate used as a tissue adhesive. Microbiyol Bul 27: 154163

*Corresponding author: Dr. Sandeep Gupta, 146, Narula Colony, The lower mall, Patiala (Pb), India, 147001, Tel: 91-9888391241; E-mail: drsandygupta@yahoo. com

Received July 21, 2011; Accepted September 12, 2011; Published October 19 2011

Citation: Gupta S, Simica (2011) Endoscopic Closure of Bronchopleural Fistula using Glue Therapy: A Case Report. J Pulmonar Respirat Med 1:103. doi:10.4172/2161-105X.1000103

Copyright: ( 2011 Gupta S, et al. This is an open-access article distributed under the terms of the Creative Commons Attribution License, which permits unrestricted use, distribution, and reproduction in any medium, provided the original author and source are credited. 